\title{
Movimiento Indígena y Poder Étnico en Colombia
}

\author{
Herinaldy Gómez Valencia \\ Universidad del Cauca, Popayán, Colombia
}

\section{Colombia, expresión de la diversidad étnica}

Zigzagueante y haciendo camino, la diversidad étnica fluye a veces escurridiza y otras abiertamente por la geografía colombiana. Descendientes de la anaconda piedra - Tuyuca-, la anaconda agua -Macuna-Sara-, la abeja del río-Carapana-, gente ceniza -Tanimuka Ufaina-, gente nube -Sirianos-, gente Zancudo -Taiwano Eduria-, gente pez -Piratapuyo-, gente paloma-Yuruti-, gente del hacha-Andoque-, gente del río de la caña silvestre - Sikuani-Guabibo-gente del territorio -Paez o Nasa Kiwe-, son algunas de las denominaciones con las que una docena de los 81 grupos étnicos indígenas de Colombia se identifican a sí mismos.

La riqueza cultural que reflejan estas sugestivas denominaciones contrasta con la pobreza estatal-institucional y muchas veces académica con que se ha querido homogenizarlas, llamándolos desde la conquista "indios".

Lo que los procesos de conquista y colonización no lograron en el orden político, económico y social, se alcanzó en el plano socio- lingüístico uniformando todas las manifestaciones aborígenes de diversidad encontrada, con la clasificación inicial de salvajes; posteriormente, y hasta hoy, con la de indígenas.

El sentido homogenizador y negativo que en sus orígenes se dio a esta designación, poco ha cambiado en el espíritu público e incluso en el académico. Su fuerza es tal que, las denominaciones específicas con que se identifican a sí mismo cada etnia, apenas comienzan a conocerse en el campo disciplinario de la antropología. Las etnias debieron, ante la dominación existente, conservar clandestinamente sus denominaciones propias y asumir ante la sociedad nacional, muy a su pesar, la de indígenas.

La denominación colonial de indígena mantiene hasta el presente una connotación anatómica; socialmente es una marca política, ideológica y cultural de condena, y no de reconocimiento de la diferencia o diversidad. Si está quieto, es un ser pasivo, si actúa es un subversivo, si está lejos -en la selva- 
es un salvaje e incivilizado, ${ }^{1}$ si retorna lo nuestro es un ser aculturado, si se rebela es un adocenado por los grupos políticos, si no cultiva la tierra intensivamente, ¿para qué entonces lucha por ella?; si la cultiva de esta manera, es un fetichizado por el consumismo, si oculta su lengua es un vergonzante, si la emplea es un malhablado, si habla español, pierde su cognición, si no la usa es un analfabeta, si se dejan por fuera de nuestra justicia quedarán a la buena de nadie y seguirán siendo criminales.

Sin negar la persistencia en el espíritu público de las anteriores connotaciones, se observa que la revigorización de las luchas étnicas en las últimas tres décadas ha servido para que académica y políticamente se comience a reconocer la vigencia de la diversidad étnica y cultural desde una perspectiva diferente. Los historiadores comenzaron a interponer a la historia oficial los fenómenos de "historias regionales y locales"; los sociólogos volvieron su mirada sobre procesos que llamaron "insurgencia de las provincias", los antropólogos cuestionaron la concepción ideológica subyacente en la denominación de indígenas y propugnan por su reconceptualización dentro de lo que significa el desarrollo de la diversidad en un Estado multicultural como Colombia.

Esta pluridimensionalidad étnica y cultural, presenta en Colombia múltiples formas de existencia y resistencia, de identidad e interculturalidad, de autoafirmación y proyección a la vida nacional, hasta el punto que las palabras de Octavio paz referidas a México pueden hacerse extensivas a nuestra nacionalidad: "En nuestro territorio conviven no sólo distintas razas y lenguas, sino varios niveles históricos. Hay quienes viven antes de la historia, otros... desplazados por sucesivas invasiones, al margen de ella... varias épocas se enfrentan, se ignoran o entredevoran sobre la misma tierra o separadas apenas por unos kilómetros...las épocas viejas nunca desaparecen completamente, y todas las heridas, aún las mas antiguas, manan sangre todavía”. (1977: 11)

En efecto, en nuestro país a pesar de las prácticas colonizadoras y de los imperios de ayer y de hoy y de los propósitos homogenizadores del Estado colombiano, la diversidad étnica continúa, a veces agónicamente en algunos espacios de la geografía y en otros se proyecta sobre la nacionalidad con mayor intensidad no solamente en sus prácticas culturales sino como dinámica social que lucha por cierta legitimidad histórica y política: el derecho a vivir plenamente su diferencia. Esta presencia étnica, y su proyección en la sociedad nacional, se manifiesta en múltiples formas; entre otras: lingüística, territorial, económica, demográfica y socialmente.

1 La ley 89 de 1890, vigente hasta 1990 habla "de los indígenas que vayan reduciéndose a la vida civilizada" 
Lingüísticamente: A pesar de que hasta antes de la Constitución de 1991 el idioma oficial era únicamente el español, las etnias han logrado conservar $64^{2}$ lenguas diferentes (hasta hoy identificadas) pertenecientes a 14 familias lingüísticas: Chibcha, Arawak, Chocó, Guahibo, Tukano Oriental, Tukano Occidental, Witoto, Ticuna, Hora, Quechua, Caribe, Macu-Puinabe, Saliba y Tupi.

Por los procesos de relación intra e interétnica e interculturales con la sociedad dominante, algunos grupos hablan únicamente su lengua nativa ${ }^{3}$ (los nuka) o el español (Yanaconas, Coconucos, Puraceños, etc.) la mayoría de las etnias indígenas andinas son bilingües, hablan la lengua aborigen y el español (Guambianos, Awa, Kamtza, Emberá Chamí, Kogüi, Arsarios, Malayos), mientras las etnias indígenas amazónicas son polilingües, hablan más de tres lenguas fuera del español (Andoque, Bora, Carijona, Desano, entre otras).

Territorialmente: No obstante las políticas estatales hasta finales de la década de los setenta de disolución de los resguardos y la declaratoria de tierras ocupadas por grupos étnicos como baldías, las etnias indígenas se encuentran esparcidas a lo largo y ancho de la geografía colombiana. Habitan en 27 de los 32 departamentos y ocupan diversas regiones ecológicas: región andina en sus tres cordilleras, desde el piedemonte cordillerano pasando por los valles interandinos hasta zonas de páramo y bosques de niebla (Awa, Yanaconas, paez, Guambianos, Emberá Chami, Kogüi, Arahuacos, Tunebo, Bari, etc.), regiones de sabana y llanura (Cuiba, Sikuani, Cubeo, Piapoco, Guayabero, etc.), regiones de selva, pacífica y amazónica (Emberá, Catio, Chami, Epera, Waunana, Witoto, Tikuna, Puinabe, Pira-Tapuyo, Nonuya, Andoke, entre otras muchas) y zonas semidesérticas (Wayú).

Las formas de relación territorial van desde el nomadismo (Nuka), apropiación rotatoria del territorio (grupos amazónicos), fronteras móviles en expansión (Paeces, Guambianos) hasta los altamente sedentarios (Kogüi, Arzarios, Arubuacos). Los resguardos y las reservas ${ }^{4}$ indígenas son la forma de

2 Este dato corresponde al Departamento Nacional de Planeación y se ha convertido en la cifra oficial. Sin embargo existe la observación de que la evaluación del número de lenguas en el país es tan imprecisa como la de la población indígena: fluctúa de acuerdo a los autores entre las 60 y 192, lo que puede dar una idea del pluralismo lingüístico...y de los problemas con que puede tropezar una política educativa que quiera respetarlo" (Gros, 1991: 268)

3 Como grupo o etnia es el único en que todos sus miembros sólo hablan el nuka Aunque en muchas otras etnias es frecuente encontrar personas que son monolingües nativos, la diferencia radica en que parte de su población habla también el español

4 Hasta antes de la Constitución de 1991 eran cuatro los tipos de estatutos que el Estado Colombiano reconocía para las tierras indígenas: El Resguardo, creación colonial que con la ley de 1890 le dio a estas tierras el carácter de posesión inalienable; la Reserva, de creación 
tenencia colectiva territorial predominante, regidas por sus autoridades en las modalidades de Gobernador de cabildo, caciques, capitanes, etc.

Económicamente: Tienen formas diversas de aprovechamiento territorial y de producción ${ }^{5}$ que van desde grupos cazadores recolectores, horticultores (región amazónica), pastoriles (Guajira), agricultores con uso microvertical del suelo (región andina), hasta grupos donde buena parte de sus miembros se emplean como obreros en ¡as minas de azufre y de sal en Puracé y Manaure respectivamente.

Demográficamente: Las etnias indígenas que han logrado resistir las prácticas genocidas y etnocidas coloniales y republicanas presentan características disímiles, los hay conformados por menos de un centenar de personas (Chiricoas, Nonuya, Pisamira, Taiwano, Yagua, Yauna), hasta los que alcanzan casi el centenar de miles (Wayú), siendo el grupo más numeroso los Paez con 110 mil. Estas características hacen que las formas políticas, económicas y sociales de relación con la sociedad mayor, den origen a prácticas sociales de interculturalidad distintas. En algunas divisiones político-administrativas del país, la población indígena representa el $0.1 \%$ (Cundinamarca) mientras en otras alcanza el 80\% de la población (Vichada).(Arango: 1992:6-11)

reciente (1965), donde la propiedad es del Estado que la da en usufructo colectivo a una comunidad indígena; la Comunidad Civil, propiedad colectiva de la tierra encabeza de miembros de un grupo étnico que carece de títulos jurídicos pero son ocupantes de hecho; el Establecimiento Individual sobre baldíos, explotaciones familiares indígenas que no disponen de una organización colectiva indígena, cuya situación jurídica puede equipararse a la de los colonos De hecho la ocupación de las tierras corresponde a territorios ancestrales y por eso los indígenas están luchando por su reconocimiento bajo el estatuto jurídico de resguardo. Los resultados del proceso político de concertación y su reconocimiento como resguardos es bien diciente, mientras en 1982 existían 73 resguardos, 79 reservas en proyecto (ONIC, I Congreso Nacional Indígena, Conclusiones documento), en 1986 el número de resguardos y reservas constituidas era de 151 y 30 respectivamente, (op cit, p.282). La Constitución de 1991 establece que los resguardos "son inalienables, imprescriptibles e inembargables" (Art.63) y reconoce como entidades territoriales "los departamentos, los distritos, los municipios y los territorios indígenas" (Art 287)

5 La tipología propuesta al respecto por el Departamento Nacional de Planeación (DNP) es la siguiente "El primer grupo (47\% de la población indígena) está formado por los agricultores establecidos esencialmente en la zona andina, y está compuesto (tal como lo define el autor del estudio), por los indígenas más integrados a la cultura blanca, que poseen modelos de producción análogos a los campesinos parcelarios El segundo grupo (32\% del total) está compuesto por cazadores, pescadores, recolectores, practicantes de agricultura complementaria, que viven en la selva (el $80 \%$ del total) y en los llanos (el 20\% del total) El último grupo ( $21 \%$ del total) está compuesto por los indios guajiros, grupo seminómada de pastores y comerciantes dedicados al contrabando que viven en el norte del país, en la frontera con Venezuela" (Arango, 1992: 270-1) 
Estos hechos permiten resaltar que el desarrollo de la diversidad es un proceso, fruto de múltiples interacciones étnicas, unas fuertes, otras débiles, que han mantenido el campo de su relación y definición en permanente agitación, un proceso que incluye al otro y al nosotros, a la sociedad estatal y a las etnias indígenas y negras. Por ello, resulta pertinente enunciar de manera sucinta, cómo los indígenas a nivel individual o parcialmente grupal han ocupado disímiles espacios de la sociedad mayor, en ocasiones intencionalmente y otras muy a su pesar.

El espacio familiar: mujeres indias que temporalmente se emplean en el servicio doméstico asumiendo muchas veces el papel socializador de niños blancos y mestizos. Aunque lo contrario es inexistente, mujeres blancas al servicio doméstico de indígenas, si hay muchas que sin prestarles ningún servicio se arrogan el "derecho" de domesticarlas.

El espacio escolar: maestros indígenas bilingües o etnolingüistas enseñando en escuelas indígenas donde confluyen blancos y mestizos; con la diferencia de que mientras los maestros indígenas se cuentan por decenas, los educadores procedentes de la sociedad dominante, se cuentan por centenas.

El espacio jurídico: abogados indígenas al servicio de mestizos y blancos y viceversa séquito de abogados blancos que luchan por ser asesores jurídicos de los actuales senadores indígenas. ${ }^{6}$

El espacio productivo: como temporeros en la cosecha nacional del café, como productores o recolectores de la hoja de coca (paeces, coyaimas, natagaimas), cosechadores de amapola, (guambianos, paeces y yanaconas), como obreros de las minas de azufre en el Cauca (coconucos, puraceños), de sal en la Guajira (wayú), en los mercados locales como cosechadores de productos agropecuarios básicos de la canasta familiar, (etnias andinas fundamentalmente).

El espacio de la salud: como médicos tradicionales (The 'walas paeces, Curacas camtza-inganos, Momarepik guambianos, Jaibanas épera-siapidara, Mamos kogüis, arsarios, etc.), consultados permanentemente por sectores sociales diversos, campesinos, mestizos, blancos y en no pocas ocasiones por los médicos alopáticos y alternativos.

El espacio de la lucha política: organizaciones gremiales étnicas que involucran en sus reivindicaciones a las de otros sectores marginales; en la lucha armada como dirigentes o militantes de organizaciones guerrilleras, movimiento armado Quintín Lame, Movimiento 19 de Abril M-19 Y Fuerzas Armadas Revolucionarias de Colombia - FARC-entre otras.

El espacio administrativo: como alcaldes e inspectores de policía. El es6 La Constitución de 1991 en el artículo 171 establece que el Senado de la República estará integrado por 102 senadores, 2 de los cuales serán elegidos por circunscripción nacional por las comunidades indígenas 
pacio legislativo, como constituyentes, senadores de la república y representantes a la Cámara.

No obstante esta gran presencia étnica en la vida nacional, ella presenta contrastes abismales, hay personas que jamás han salido de su territorio étnico y desconocen los símbolos patrios más comunes como la bandera y el himno nacional, pero también los hay que por su carácter de dirigentes conocen países de los cinco continentes.

Aunque no hay estudios sobre el impacto de estas formas de intervención étnica en la sociedad nacional, sí se constata que el impacto de la sociedad nacional y del Estado en toda su existencia, en vez de desarrollar la diversidad ha acrecentado la desigualdad. Ninguna de las etnias indígenas ha logrado alcanzar los niveles de vida y bienestar material que existían en la época precolombina.

Aunque la pobreza económica que hoy presentan algunos grupos (cuya esperanza de vida al nacer es de 36 años, 20 años menos que el colombiano medio, y tazas de mortalidad infantil de 233.2 por mil, contra el 87.0 del promedio nacional) contrasta con la riqueza cultural, espiritual y de conocimiento que aún poseen, resulta injustificable seguir reproduciendo tal desbalance, ya que como lo expresa un The'wala paez "no sólo se puede vivir de pensamientos, todo lo que vive necesita alimentarse, también nuestros héroes ancestrales se alimentan de nuestros pensamientos y de los productos que les ofrecemos", "los indígenas podemos pensar y hablar distinto, pero todos sufrimos de lo mismo, el gobierno blanco nos está volviendo iguales, cada día tenemos menos fuerza para trabajar, nos está volviendo iguales en lo malo y no en lo bueno".

Es cierto que esta heterogénea y abigarrada presencia de la diversidad étnica en el país, es producto de las luchas étnicas de resistencia cultural, de la defensa solidaria de sus territorios, de la transformación, reconstitución y adaptación permanente de su identidad, y de la dinámica económica, social y política propia del sometimiento impuesto por el Estado y sociedad nacionales. Sin embargo, es necesario reconocer que a partir de fines de la década de los sesenta, dicho proceso toma dimensiones diferentes, debido especialmente al surgimiento de nuevas estrategias de organización de la lucha étnica y del cambio estatal de la política indigenista.

En efecto, fue sólo a partir de la década del setenta que las luchas étnicas y las prácticas discursivas de líderes indígenas asumieron un carácter organizativo y político de mayor proyección hacia el Estado y sociedad nacionales. Continúa así, y a otro nivel, la lucha reivindicativa y de afirmaciones culturales que interna, aislada o localmente venía desarrollando cada etnia. 
La generalización de las luchas campesinas por la tierra y la necesidad de una reforma agraria, contribuyeron a la creación en 1970 de la Asociación Nacional de Usuarios Campesinos (ANUC), en cuya conformación participaron y tuvieron asiento las comunidades étnicas a través de la secretaría indígena.

Posteriormente el sector indígena sintió la necesidad (dado el carácter diferencial de sus reivindicaciones y de concepción política frente a las planteadas por la dirigencia del sector campesino de la ANUC), ${ }^{7}$ de crear su propia organización que contribuyera al desarrollo de un movimiento indígena unificado y asumiera una posición mas militante de lucha por la tierra mediante la ocupación de facto (recuperación) de los territorios de resguardo usurpados por los terratenientes. La iniciativa surgió entonces en aquellas regiones con mayor trayectoria de lucha como el Cauca, donde se crea el Consejo Regional Indígena del Cauca (CRIC) el 24 de febrero de 1971, en el municipio de Toribío Cauca, con un programa político- cultural de siete puntos: Recuperar las tierras de los resguardos. Ampliar los resguardos. Fortalecer los cabildos indígenas. No pagar terraje. Hacer conocer las leyes sobre indígenas y exigir una justa aplicación de ellas. Defender la historia, la lengua y las costumbres indígenas. Formar profesores indígenas para educar de acuerdo con la situación de los indígenas y en su respectiva lengua.

La generalización de las luchas étnicas, los logros alcanzados por esta organización, lo apropiado del programa, conducen rápidamente al surgimiento en muchos otros departamentos de organizaciones regionales indígenas, hasta llegar a la conformación de dos organizaciones nacionales como la Organización Nacional Indígena ONIC en 1982 y el Movimiento de Autoridades Indígenas de Colombia, AICO en 1988.

El surgimiento y posterior desarrollo de las organizaciones regionales, dio un nuevo sentido a las estrategias de resistencia (defensa) cultural proyectándolas en un movimiento de confrontaciones (movilizaciones) a nivel nacional durante toda la década del setenta. Durante esta década se produjo el mayor número de movilizaciones indígenas, de recuperaciones de tierra, de asesinato de líderes indígenas por parte de los paramilitares al servicio de los terratenientes, de enfrentamiento con la fuerza pública. A la vez el movimiento sufrió el más alto grado de represión estatal (tomas militares, allanamientos, torturas, encarcelamientos y muerte de dirigentes). Igualmente la política estatal tuvo su mayor arremetida jurídica con la iniciativa del gobierno de Turbay Ayala de crear el "Estatuto Indígena”, con el cual pretendió

7 Para una ampliación de las razones de distanciamiento entre la ANUC y el Movimiento Indígena, véase: Colombia Indígena. Identidad Cultural y Cambio Social El "Despertar Indígena" (Gros, 1991) 
acabar con la organización y reivindicaciones del movimiento. La respuesta indígena afortunadamente logró dar al traste con este reaccionario propósito. Desde 1982 con la creación de la ONIC, se configura una nueva estrategia, las dirigencias del movimiento y/o de sus organizaciones adoptan nuevos comportamientos y funciones caracterizados por prácticas y discursos más convencionales y conciliadores. La negociación y concertación con el Estado e instituciones públicas y privadas domina la dinámica política del movimiento. Aspecto por demás acorde con los procesos de paz que Colombia comenzó a vivir a partir del gobierno de Belisario Betancourt. ${ }^{8}$

Las nuevas estrategias posibilitaron una mayor difusión de las reivindicaciones étnicas, ganando cada vez mas presencia y legitimidad social, nacional e internacional. Pero este posicionamiento también significó una transformación en las relaciones entre las dirigencias y las bases locales del movimiento.

A diferencia de las grandes movilizaciones por tierras (territorio), donde los dirigentes se encontraban por razón de las luchas de recuperación, estrechamente ligados a las comunidades, posteriormente, las dirigencias se van distanciando cada vez más de sus bases étnicas debido a que, el crecimiento de sus organizaciones, la tregua con el Estado, la demanda por mejores servicios y por programas de desarrollo, los va ubicando paulatinamente en los “espacios privilegiados de las intermediaciones e interlocuciones", alejándolos cada vez más de la confrontación y acometida contra el Estado y sociedad nacionales.(Sánchez: 1986).

8 La posición gubernamental asumida por el presidente Belisario Betancourt contrasta radicalmente con la de su antecesor Julio César Turbay. A diferencia de lo pretendido por este último con el "estatuto indígena", Betancourt en un acto, "signado por su carácter democrático pero también de retórica populista”, decidió ante millares de indígenas congregados en una recuperación de tierras que "había pertenecido a una de las más poderosas familias de los barones del azúcar" iniciar directamente un diálogo gobierno comunidades indígenas Aunque el discurso pronunciado configura la política indígena de su gobierno, se retoma aquí apartes de lo atinente \&! diálogo y problema de tierras; "Este diálogo no puede iniciarse sin el reconocimiento de las injusticias que hemos cometido y sin el propósito de impulsar un cambio de situaciones creadas al amparo de una legalidad mal entendida y mal aplicada"."y sé en fin señores gobernadores (indígenas), señores miembros de las comunidades indígenas, fin, que el problema esencial es el de las tierras Pues bien el Estado tomará las medidas tendientes a que ella regrese dentro de la ley a los legítimos dueños, mediante la intervención de las oficinas del Estado a cuyo cargo y bajo cuya responsabilidad queda el cumplimiento de esta tarea" (paréntesis agregado) Discurso ampliamente divulgado por la prensa y en documentos de las organizaciones indígenas 


\section{Entre la participación y la cooptación}

El espacio de las intermediaciones e interlocuciones de por sí, genera una competencia que exige un nuevo perfil de los líderes étnicos. No son las tradicionales "autoridades étnicas", que ocupan el ámbito local de las luchas, quienes se ubican en los espacios de dirección de las nuevas organizaciones. La nueva situación requiere de actores sociales que hayan tenido más contacto con la sociedad nacional, que se desenvuelvan mejor en ella, que puedan exponer "mas claramente las ideas" que sus prácticas sociales y discursivas "sintonicen" más con las propias del sistema institucional y estatal.

La educación formal, el uso del español, el manejo de la escritura, la experiencia institucional, las relaciones políticas con otros sectores, la disponibilidad o capacidad de poder vivir por largos períodos fuera del lugar de origen, -y no tanto la identidad étnica, la trayectoria de las luchas locales, y el conocimiento de prácticas sociales-, son los factores que entran en la competencia para ocupar la mayoría de los cargos directivos de las organizaciones.

De esta manera se permite que sean las nuevas generaciones las que entren a jugar un papel importante en la lucha a nivel externo, sin que ello implique necesariamente un desplazamiento de las autoridades intraétnicas o la adquisición de un poder especial para intervenir a nivel interno en las decisiones de la comunidad. Su participación en los espacios intraétnicos sigue pasando por los mismos procesos de recomunalización del poder, propios de cada cabildo y/o etnia.

El crecimiento de estas organizaciones, sin escapar a los vicios del burocratismo, verticalismo, juego político de intereses particulares, su mayor acercamiento al Estado, y muy especialmente, la "preferencia" de las organizaciones por negociar y concertar con el Estado y por la participación electoral, y no por las confrontaciones y movilizaciones, han llevado a pensar a intelectuales, políticos, sectores radicales de izquierda, que el movimiento ha sido o está siendo cooptado por el Estado.

La ausencia de un análisis integral del despliegue de formas de poder étnico, hacen que el problema así planteado adolezca de perspectiva histórica y visión política. Históricamente, porque se olvida que no es la primera vez que el Estado ha penetrado en los grupos étnico s imponiéndoles siempre instituciones ajenas a su identidad. No obstante, las etnias han generado respuestas adaptativas y de refuncionalización propias, como las realizadas respecto al resguardo y al cabildo, instituciones que, a pesar de su origen español, fueron adoptadas y adaptadas a las formas culturales propias, hasta el punto de que hoy son elementos esenciales con los cuales se identifican y hace parte de la 
cultura indígena. Políticamente, porque desconoce que el ejercicio del poder a nivel de la organización gremial indígena, no es el mismo que el del nivel interno de las etnias.

El dilema posee connotaciones políticas muy diferentes a las de la "simple” cooptación. Dos aspectos bien delimitados pero interrelacionados definen la naturaleza del problema en cuestión.

Antes de llegar a la afirmación de que el movimiento está siendo cooptado por el Estado debido a los hechos antes señalados, resulta políticamente más pertinente comenzar a evaluar si los cambios de desplazamiento de la politicidad étnica y su efecto distanciador de las bases se compaginan con las cuotas mínimas de participación obtenidas en las instancias de poder del Estado y sociedad nacionales y con la capacidad de concertación y negociación con las instituciones gubernamentales, y si estas cuotas son o no suficientes para defender en estos espacios los intereses étnicos. Cosa por demás distinta a la de afirmar que el avance del movimiento étnico esté más en función de las acciones de confrontación políticas, sobre asuntos puntuales, desarrollados en espacios tan marginales de la sociedad nacional como los territorios étnico s, desvalorizando de paso y desconociendo la fuerza y significado que tienen otras formas de intervención política como las desarrolladas hasta ahora por el movimiento indio en el avance y defensa de su causa.

La valoración crítica que las organizaciones y l-as etnias hacen de esta problemática, no les impide reconocer que las estrategias políticas deben cubrir simultáneamente ambos espacios (interno y externo), de ahí que jamás ahorren esfuerzos para criticar permanentemente lo que sucede en cada espacio de la lucha. La historia de sus triunfos y derrotas son el soporte para el empleo de estas múltiples estrategias. Muchos de sus conflictos internos derivan de las relaciones con la sociedad nacional y el Estado y saben que la solución depende tanto de su cohesión interna, como de su articulación a los procesos políticos más globales de la sociedad. Si las relaciones no cambian, los conflictos seguirán.

Son coincidentes las apreciaciones de autoridades étnicas que jamás han estado en la dirigencia gremial, con las declaraciones de quienes son parte de ella, en el sentido de que el proyecto de vida étnico sólo es posible si hay cambios en las etnias y en la sociedad nacional. Cambios a lograr fundamentalmente por los senderos de la paz y la concertación, y no necesariamente por la guerra.

Es en este sentido que el movimiento valora la combinación de múltiples estrategias como solidarias del mismo proceso, no sólo porque la diversificación es inherente a la politicidad étnica y sus formas de vida sino también 
porque ellas hacen más eficiente el proyecto de resistencia a más largo plazo.

Reclamar para el avance del movimiento indígena un repliegue hacia las pasadas formas de lucha (confrontación, movilización, propias de las década del setenta), y la transformación de las actuales dirigencias de las organizaciones, es caer en posiciones políticas idealistas y voluntaristas. Lo primero, de una parte, por considerar que el pensamiento indio es o ha de ser uno y no múltiple como lo es en realidad (la diversidad de culturas les imprime tal naturaleza); de otra, por creer que existe homogeneidad en las formas de representación propiamente étnicas y las del movimiento, exigiendo por lo tanto relaciones sin tensiones. Lo segundo, por creer que el problema es la política -cambio de las formas de lucha y de actores sociales-, y no de las diferencias de naturaleza existentes entre los modelos de organización del poder propio y los modelos exigidos, legitimados (reconocidos jurídicamente) por el Estado y la sociedad nacionales. "En una tradición cultural donde el poder tiende a ser ampliamente compartido, la delegación del poder esencial a los modelos de representación, resulta un procedimiento poco desarrollado en el medio andino, que genera serios problemas, sobre todo en el caso de las organizaciones indígenas" (Sánchez: 1990:49)

Explicar políticamente el paso de las confrontaciones y movilizaciones al de la negociación y concertación como cooptación del movimiento y sustentarlo por las prácticas del burocratismo, verticalismo, autoritarismo, es quedarse en sus manifestaciones o expresiones más superficiales. Se trata de un fenómeno sociológico que comienza a transformar la naturaleza del poder étnico haciendo que éste comience a construirse a imagen y semejanza de como se produce y ejercita el poder en occidente. De la misma manera que en estas sociedades el Estado se constituye en un poder/autoridad, separado de la sociedad o contra ella, de igual manera comienza a conformarse en la estructura organizativa del movimiento indígena un poder/autoridad separado de las etnias y en ocasiones contra ellas. Hecho que pone de presente que el problema no es de política ni del tipo de actores y por lo tanto tampoco de cooptación.

La percepción de la problemática por parte de algunas autoridades étnicas (médicos tradicionales paeces y guambianos, entre otros) deja traslucir su claridad sobre la naturaleza del problema. Para ellos es claro que el asunto no obedece al cambio o uso de nuevas estrategias de participación, afirman que prefieren la concertación al enfrentamiento y la paz a la guerra. Los paeces dicen "sentir", los guambianos dicen "ver" que lo que está ocurriendo es un cambio de pensamiento que se aleja de la enseñanza de los taitas o de los mayores, por ello plantean que, "hay que beber en las fuentes del saber propio, 
no en las del saber blanco"; "debemos cerrar el cuerpo para que no ganemos las enfermedades del blanco: crisis de amistad, crisis de desconfianza” (Sic); "los mayores lucharon contra el egoísmo, por eso estamos aquí en el camino de la lucha, si ganamos tierra no es sólo para nosotros, es para compartirla con todos los animales, ellos también viven en ella"; "solos no podemos avanzar, trabajemos con el gobierno sin perder el camino".

Las diferencias y tensiones entre las dirigencias del movimiento y las autoridades étnicas, no radica en el cambio de las estrategias, aceptan y reconocen la validez e importancia de la negociación y concertación con el Estado, ven como signo positivo la presencia étnica en el ámbito exterior -vida nacional- . Su exigencia está en el ámbito de la cultura y su relación con la política. En la acción del afuera debe estar presente el adentro: el pensamiento de las etnias, los sustentos de la cultura, los modos de ser, actuar y pensar propios y no los del mundo occidental.

No hay razón para ver en ello deseos de hacer de su lucha un movimiento fundamentalista o con concepciones próximas a los actuales nacionalismos, las etnias o el movimiento, no tienen enemigos o rechazos hacia hombres en particular, ni por razones de raza, creencias u origen. Su "oposición” no es hacia el blanco, negro, mestizo, ni hacia el Estado - Iglesia, e instituciones etc., a lo que se oponen es a que éstos quieran imponerles sus pensamientos, formas de ser y actuar. Se trata más bien de que el movimiento tenga identidad (es) para que les sea reconocido su derecho a ser diferentes, que su lucha por el mejoramiento de su calidad de vida no pase necesariamente por ser la copia del mundo occidental tal como históricamente éste lo ha exigido.

Así las cosas, lo que se vislumbra en el horizonte del movimiento indígena no es un retorno a, sino un receso de las "viejas" formas de lucha: recuperación de tierras, lucha armada, movilizaciones públicas. En las bases intraétnicas lo que se está generando es el desarrollo y recomunalización de conocimientos y prácticas culturales a través del saber de sus mayores y la enseñanza de sus ancestros. En uno y otro espacio (organizaciones indígenas y etnias aunque más en éstas), la estrategia se orienta hacia la recuperación de pensamientos étnicos que den identidad a sus habituales afirmaciones culturales. La aceptación en las bases étnicas de los discursos políticos renovadores, de líderes étnicos como Lorenzo Muelas (Guambiano) y Jesús Piñacue (paez), su reconocimiento en los espacios de dirección del movimiento, conjuntamente con la revitalización de las culturas médicas étnicas, la revalorización de las lenguas aborígenes, el fortalecimiento de formas de derecho étnico y sentido de adscripción territorial, son ejemplos claros entre otros, del proceso de reconstitución de identidad y del poder étnico. En palabras 
de Bonfil Batalla "su aspiración es cambiar la realidad y no la de cambiar de realidad que es muy diferente" (1991: 17)

Parodiando aquellas frases de que "el ojo es ojo, no porque lo ves sino por que te ve" y que "lo esencial es invisible al ojo", entre las etnias andinas, el poder es poder, no porque lo ves, sino porque no lo puedes ver. Por ello su reproducción no necesita de instituciones, ni de ejércitos, ni de jueces, ni de organizaciones, sólo requiere un territorio y sujetos con identidad cultural, que si bien se les reconoce el carácter de líderes, no se arroguen por ello el derecho a dirigir o ambicionen el poder. En palabras del ideólogo y dirigente indígena boliviano, Fausto Reynaga Chavarría "cuando en la comunidad india, alguien quiere ser jefe o quiere dirigir, por el mismo hecho se le inhabilita como jefe" (1994:70).

Independientemente del análisis y valoración que pueda hacerse de las formas de lucha y estrategias políticas interpuestas por el movimiento indígena, lo cierto es que los logros hasta hoy alcanzados permiten hablar de la existencia, reconocimiento y legitimidad del proyecto político étnico. A manera sólo de identificación y aceptando la dificultad encontrada para una elección juiciosa de dichos factores, se traen a colación algunos de los que en el ámbito político aparecen como más representativos o significativos.

El afloramiento de los movimientos étnicos indígenas y el acrecentamiento de sus luchas y participación política en diferentes espacios de la vida nacional, han creado de hecho realidades políticas que "tocan el orden nacional y los fundamentos ideológicos del Estado-Nación en cuyo seno se pretende integrarlos". Por el contenido de sus reivindicaciones y las formas de luchas empleadas y su articulación con otros sectores de la sociedad, estos movimientos trascienden su realidad exclusivamente étnica y se aproximan a los movimientos reivindicativos "nacionales" "oscureciendo las fronteras entre etnia y nación”. (Jimeno, 1985: 18)

De hecho, las prácticas políticas y discursivas que definen al actual movimiento indígena y la formación de actores indígenas, además de su especificidad étnica, contienen planteamientos y reivindicaciones dentro y frente al mismo Estado y sociedad nacionales.

El conjunto de los aspectos anteriores ha contribuido a la "nacionalización” de la cuestión étnica ya que su misma inscripción en la historia nacional haya permitido a las etnias conquistar espacios de interlocución, negociación y concertación con el Estado y sectores sociales, ubicándolas a las vez, no sólo como protagonistas de su propia historia sino también como actores de la historia nacional. 
Esta progresiva presencia de lo étnico y sus actores en la historia nacional, muestra cómo los grupos étnicos han pasado de pensarse a sí mismos a escala local, intra e interétnica, para presentarse a través de sus discursos y prácticas en un ámbito socio espacial que da a sus luchas un alcance nacional, colocándolos en la posibilidad de constituir un proyecto étnico-cultural para el desarrollo de su etnicidad.

De hecho y de derecho, el proyecto étnico y su proyección política en la vida nacional tiene su sustento mayor en realidades culturales más perdurables y menos coyunturales que las del espacio social de participación política. Las etnias indígenas presentan en la actualidad sistemas de vida, social, política, económica y cultural distintas a las dominantes en la sociedad mayor. Las expresiones más diversas pueden encontrarse, culturalmente: en la recuperación de sus lenguas nativas, sistemas de cognición, sistemas médicos, ritos y mitos. Económicamente: en la reestructuración de sus relaciones de parentesco, mecanismos de reciprocidad y distribución, fortalecimiento de las formas de trabajo comunal, ayuda mutua, propiedad colectiva de la tierra y apropiación comunitaria de los recursos disponibles del medio. Jurídicamente: en la existencia de sistemas de derecho étnico para prevenir, sancionar y rehabilitar conductas culturalmente desviadas. Políticamente: en el reforzamiento de sus formas de organización y de gobierno intraétnico representado en cabildos, caciques, capitanes y en autoridades étnicas como consejo de ancianos, médicos tradicionales. Socialmente: en el acrecentamiento de su sentido de pertenencia territorial y adscripción grupal específicos.

Los elementos precedentes, a pesar de las múltiples contradicciones existentes, (propias por demás de todo proceso de reconstitución y transformación cultural), si bien por la misma razón no poseen igual desarrollo o vigencia en cada etnia, son algunos de los aspectos que se muestran como más resistentes al cambio y su perduración en el tiempo hace parte de los procesos de "larga duración".

Son igualmente estos aspectos de singularidad étnica los que más chocan con las políticas y el mito de homogenización propuestas por el Estado. Quizá el ejemplo más representativo pueda ser que el territorio, concebido como madre tierra, y la fuerza de trabajo, entre las etnias, están reguladas por la comunidad y no por el mercado, obstaculizando el libre acceso a la tierra, a la fuerza de trabajo y a los recursos naturales, frenando la generalización de la propiedad privada base del sistema de producción capitalista sobre el cual se organizan algunas de las funciones económicas del Estado.

No es gratuito que el derecho a la tierra como territorio, sea el problema mayor sobre el cual las etnias han fundamentado históricamente sus luchas y 
por el cual han sido víctimas de la mayor represión estatal. Los encarcelamientos en Colombia por este motivo en las últimas tres décadas, se cuentan por millares, los asesinatos por la fuerza pública, terratenientes, paramilitares, se cuentan por centenas, y no son pocos los genocidios. Para una ampliación de este problema ver: "El CRIC denuncia" 1979 y "Diez años de lucha: Historia y documentos" 1981. No obstante estas formas de violencia generalizada, llama la atención que las etnias indígenas, a pesar de no representar "mas del 2\% de la población del país" (aproximadamente 600.000 habitantes), en "la actualidad posean cerca del $25 \%$ de la superficie total de Colombia"(Padilla. 1993:128-9)

Sin territorio y el derecho comunal a regularlo, las etnias saben que pierden su razón de ser, de ahí que su defensa asuma el carácter de un enfrentamiento radical con el Estado, sectores de la sociedad, y en ocasiones, interétnicamente.

La versatilidad de las estrategias políticas y organizativas del movimiento, no sólo hizo que aflorara en toda su dimensión el problema étnico y su lucha por la tierra sino que también obligó a que las políticas estatales tuvieran un cambio sustancial a partir de mediados de la década de los ochenta. Pasó de ser un asunto de políticas unilaterales estatales para convertirse en un asunto político de negociación y concertación. Del desdén por 10 étnico, propio de las décadas precedentes se pasó rápidamente a su valoración como aspecto de interés público nacional. El cambio de percepción frente a 10 étnico parece obedecer a la confluencia de por 10 menos dos factores centrales, el externo o internacional y el interno o nacional.

El factor externo tiene que ver con la construcción de un marco jurídico y legal que dio mayor legitimidad a las luchas étnicas en el mundo, entre las cuales vale la pena destacar: las declaraciones I y 11 de Barbados de 1971 y 1977 respectivamente, la declaración de la Comisión Interamericana de los Derechos Humanos de la OEA; el Convenio 169 de 1989 de la OIT; la Resolución 45/164 de las Naciones Unidas de 1990 que proclamaba a 1993 como Año Internacional de las Poblaciones Indígenas del Mundo; la Declaración de Río en la reunión de Ecomundo en 1992.

El factor interno tiene como relevante, la conformación de organizaciones gremiales indígenas a nivel nacional que dieron una nueva dimensión a las organizaciones regionales, como la Organización Nacional Indígena de Colombia ONIC y la de Autoridades indígenas de Colombia AICO; los procesos de paz con el M-19; y el EPL, en cuyo seno no sólo hubo indígenas sino que se reivindicó la causa étnica; y de manera especial el proceso de paz con el Movimiento Indígena Armado Quintín Lame que entre su agenda de 
negociación logró recursos para impulsar planes de desarrollo que contenían reivindicaciones generales municipales; la participación de líderes étnicos en la Asamblea Nacional Constituyente que alcanzó reformas substanciales para el futuro étnico en la Nueva Carta Constitucional Colombiana.

La importancia de las reformas puede deducirse fácilmente de lo consagrado en los artículos 7, 8,10, 63, 246, 286 y 330 de la Constitución Nacional, ${ }^{9}$ entre otros. Dichas reformas no son campo exclusivo de la realidad colombiana, por el contrario ellas surgen "tardíamente" pero quizás con un mayor avance legal, en el marco de las transformaciones constitucionales, generalizado en América Latina. Reformas "similares" existen en las Constituciones de Perú (1979), Guatemala (1985), Nicaragua (1986), Brasil (1988), México (1990), Paraguay (1992). El sentido y trascendencia legal de estas reformas nadie lo pone en duda, lo que está en cuestión es la voluntad política de los gobiernos, la capacidad organizativa étnica, la sensibilidad civil y la disponibilidad de los recursos económicos para desarrollarlas y ponerlas en práctica.

Imposible desconocer que este cambio de percepción política (global y nacional) frente a la cuestión étnica no deba ser igualmente sometido al análisis de lo que a nivel mundial está pasando en el orden político y económico.

$\mathrm{Al}$ respecto se plantea que tales transformaciones obedecen a una nueva economía del ejercicio del poder, del viejo sistema del poder basado en la "exacción-violencia", se está pasando al de la "suavidad-producción-provecho" (Foucault. 1978). Los Estados continúan ejercitando una doble política de reprocesamiento de la integración: a la vez que en las prácticas discursivas, en la esfera jurídica y política formulan un respeto y reconocimiento de la

9 Los artículos de la Constitución Nacional mencionados establecen: "El Estado protege la diversidad étnica y cultural de la Nación Colombiana" (Art. 7). "Es obligación del Estado y de las personas proteger las riquezas culturales y naturales de la Nación” (Art. 8). "El castellano es el idioma oficial de Colombia. Las lenguas y dialectos de los grupos son también oficiales en su territorio. La enseñanza que se imparta en las comunidades con tradiciones lingüísticas propias será bilingüe” (Art. 10). “...las tierras comunales de grupos étnicos, las tierras de resguardo, el patrimonio arqueológico de la Nación y de los demás bienes que determine la ley, son inalienables, imprescriptibles e inembargables" (Art. 63) "Las autoridades de los pueblos indígenas podrán ejercer funciones jurisdiccionales dentro de su ámbito territorial, de conformidad con sus propias normas y procedimientos siempre que no sean contrarios a la Constitución y leyes de la República” (Art. 246). "Son entidades territoriales los departamentos, los distritos, los municipios y los territorios indígenas" (Art 286). "De conformidad con la Constitución y las leyes, los territorios indígenas estarán gobernados por Consejos conformados y reglamentados según sus usos y costumbres en las comunidades" (Art 330). 
diversidad étnica, tratan de absorberla a través de sus aparatos y programas de desarrollo.

Pero aún así, resulta relevante destacar que el resurgimiento de lo étnico obliga a preguntarse igualmente sobre ¿cuáles son lo límites que la diversidad cultural crea a la globalización de la economía, y hasta qué punto ésta amenaza la pluralidad étnica? De hecho en el pasado y también en el presente el problema participa de un proceso de doble vía: es innegable que la globalización económica afecta negativamente a la persistencia de las etnias, pero los valores y el sentido de identidad que genera el pertenecer a un grupo étnico no tiene necesariamente porqué desaparecer ante la presión y desarrollo de la economía capitalista.

La historia muestra desarrollos a favor y en contra de los procesos en contradicción. Hoy la diferencia radica en que no es el "libre" desenvolvimiento de lo económico y lo étnico el que demarca el camino del conflicto, por el contrario, la conciencia y el conocimiento histórico de proyectos fallidos, marcados por la sujeción y confrontación, hacen que en el presente la alternativa al conflicto sea una salida políticamente negociada y concertada, máxime si la "correlación de fuerzas" constata la simultaneidad de dos intensificaciones legitimadas: la de la globalización económica y la de la afirmación étnica. Ambas vuelven la problemática un asunto esencialmente político y de poder.

Los nuevos derroteros de la democracia y la postmodernidad, han 'dado un viraje al desarrollo de la diversidad étnica y cultural, haciendo de ésta una realidad que hay que defender antes que atacar. Se ha llegado así, a que la autonomía étnica otrora negada sea ahora reivindicada; la persistencia de formas étnicas de relación ecológica con el medio consideradas como contrarias al desarrollo, sean hoy parte del desarrollo sostenible o sustentable.; los actores étnicos catalogados como enemigos del establecimiento sean interlocutores o voceros legítimos del Estado; la diversidad étnica categorizada como obstáculo para la formación del Estado-nación sea reconocida como constitutiva de su realización.

La convergencia de factores favorables a la cuestión étnica, como la consagración de derechos étnicos en la Constitución Nacional, la institucionalización de algunas de sus reivindicaciones, la sensibilidad social sobre su problemática, la legitimidad y reconocimiento de la participación de actores étnico s en la vida política nacional, la creación de espacios específicos para la concertación y discusión de asuntos étnicos, fácilmente pueden llevar a pensar que la cuestión étnica en Colombia está a punto de ser resuelta. Una convicción semejante presenta políticamente varias confusiones. El cambio de la política estatal y de percepción frente a lo étnico, no significa que se presen- 
ten transformaciones similares en tomo a lo político de la cuestión étnica, una cosa son las reivindicaciones étnicas manifiestas en los procesos de lucha y concertación con el Estado y otras muy distintas, las que intraétnicamente se ejercitan para el desarrollo de su etnicidad y la valoración política que estos hacen del Estado.

\section{El poder, fundamento de la cuestión étnica}

Sobre la base de lo precedentemente expuesto, es un hecho que la realidad del fenómeno étnico en nuestro país ha perdurado y permanentemente ha sido reconstituido históricamente, no en una relación de diferencia étnica, sino en una relación política de constante conflicto y confrontación, y bajo un sistema de relaciones signadas por la dominación, marginalidad y exclusión. A estas formas de poder imperial y/o estatal, las etnias indígenas han respondido política y socialmente de manera diversa, dependiendo de las circunstancias y las condiciones y concepciones específicas de cada grupo étnico.

Las reacciones políticas interpuestas podrían agruparse por lo menos en tres tipos: Las que van desde la guerra hasta la "aceptación" de formas de dominación; las que implican procesos de resistencia cultural abierta, hasta las de una aparente subordinación; y las que presentan confrontaciones temporales hasta procesos de negociación y concertación con el Estado y sociedad nacionales. Aunque dichas formas de reacción no tienen un orden de sucesión histórica y en la realidad pueden darse todas, o de manera alternada en un mismo grupo, lo cierto es que en el presente aparece como dominante o privilegiada la concertación y negociación para cuyo logro puede recurrirse si es necesario a confrontaciones temporales de baja intensidad.

Si lo político y el poder político son inherentes a todo grupo humano y se conoce que lo étnico ha sido reconstituido bajo formas de politicidad y ejercicio del poder interpuesto por las etnias ante los ejercidos por el poder estatal, resulta claro que las formas de poder étnico son parte constitutiva de la cuestión étnica. La comprensión de la cuestión étnica y la etnicidad, por fuera de la relaciones de poder y centrada exclusivamente en la especificidad de las esferas económica y cultural, resulta insuficiente. Tales centramientos constituyen el obstáculo mayor para una compresión política del fenómeno étnico en Colombia. Este fenómeno se toma más llamativo y hasta contradictorio en relación con las etnias indígenas, que se han reproducido como sociedades sin Estado y cuyas formas comunales han seguido haciendo de ellas "sociedades contra el Estado" (Clastres. 1974) 
Varios, y de diferente naturaleza, son los aspectos que han contribuido para que en la reflexión sobre la cuestión étnica haya permanecido invisible la especificidad de las formas y formaciones de poder intraétnico. Uno de estos aspectos, como lo plantea Sánchez Parga, obedece a que en los países andinos "donde la sociedad civil se ha desarrollado deficitariamente y el Estado ha adquirido una hipertrofia, el modelo de representaciones estatales tiende a hacerse tan ubicuas, que todas las formas, sectores y organizaciones societales se constituyen y configuran por referencia a él, y tienden así mismo a mimetizar el modelo del Estado y sus aparatos". (1990:95)

Un segundo aspecto, derivado del fenómeno anterior, es que las organizaciones gremiales a nivel regional y nacional se han visto obligadas a retomar mecanismos del modelo estatal y adoptar un funcionamiento análogo que les resulta funcional para negociar y concertar con el Estado y relacionarse con él. Esta forma de proceder organizativo, por demás generalizado en los espacios de la sociedad nacional, ha conducido a creer, en el mejor de los casos a suponer, que el poder étnico se organiza externamente de la misma manera que a nivel interno.

En Colombia, los más destacados analistas de la cuestión étnica son solidarios de esta interpretación. Sobre la base de la creciente proliferación de organismos indígenas, de las manifiestas contradicciones y faccionalismos políticos, de la cada vez mayor participación en los aparatos del Estado, y especialmente por la reproducción de vicios burocráticos e institucionales que modificaron las "viejas" prácticas de enfrentamiento y resistencia india por las de la concertación y negociación, argumentan que lo étnico está siendo cooptado y absorbido por el Estado. De aquí, a poner en cuestión el poder étnico, la etnicidad y la singularidad del movimiento, no hay sino un paso.

El tercer aspecto, y quizá el más importante por explicar en parte los anteriores, responde a la ausencia en Colombia de estudios sobre la trama del poder étnico, sobre la persistencia de formas tradicionales de politicidad en los espacios comunales y sobre la dinámica de esta politicidad en los espacios del Estado y sociedad nacionales. En su defecto, lo que sí ha proliferado son los análisis sobre la participación étnica en la vida nacional, en los que se enfatiza sobre los impactos negativos de la política estatal y eclesiástica en la vida comunal étnica. El estatismo propio de estos análisis sólo permite identificar la extensión o instauración en las etnias de los aparatos del Estado sin observar los procesos de refuncionalidad dados a éstos por parte del poder étnico.

El cuarto aspecto es de índole teórico y metodológico. Deriva de la concepción de que el poder y su ejercicio tienen sinonimia con los aparatos e instituciones "encargados" del poder, y, en consecuencia, hay que buscar su 
presencia en las etnias únicamente en aquellas representaciones que guardan semejanza con el funcionamiento del poder estatal. El poder y lo político en las sociedades étnicas, a diferencia de las estatales, "permanece" regularmente en el estrato de lo implícito o "intermitente" o bien, difuso en la diversidad de prácticas sociales. En consecuencia, las formas y formaciones del poder étnico son distintas a las estatales y por lo tanto no se encuentran representadas en aparatos o instituciones especializados. La naturaleza de este poder, los contenidos que éste da a la etnicidad, las condiciones de su producción y reproducción, la dinámica que adopta su ejercicio en los diferentes espacios en los cuales se expresa, pasa necesariamente por el análisis de las relaciones y prácticas culturales comunales.

La lucha étnica no es un movimiento por el poder estatal, tal aspiración desnaturaliza las formas culturales de producción del poder étnico. Aunque parezca contradictorio, un nivel de la lucha se expresa en la resistencia a establecer intraétnicamente las formas de poder estatal u occidental, pero al mismo tiempo tampoco busca la implantación de sus formas de poder en la sociedad nacional. Este es el límite crítico del poder étnico y de las relaciones de poder con el Estado y sociedad nacionales. Límite que señala su diferencia étnico-cultural y político con el poder estatal y establece a la vez su diferencia radical con las luchas de los demás sectores sociales. Diferencia que no es comprendida ni política ni culturalmente por los partidos políticos, organizaciones de izquierda, el Estado y sociedad nacionales.

El carácter difuso, temporal y circulante del poder étnico y su producción comunal "inconsciente", impiden que su "naturaleza." aflore o se manifieste explícitamente tanto en las prácticas discursivas como en sus reivindicaciones. La persistencia o resistencia del poder étnico frente a las formas de poder estatal se manifiesta o se actualiza en la crítica permanente de las bases étnicas a las dirigencias del movimiento indígena, en retirarles su apoyo o mantenerlo condicionalmente, en controlar su participación en los asuntos internos de las etnias. Comportamientos que si bien objetivamente no siempre impiden a los actores políticos una acumulación del poder, subjetivamente opera como principio de control social.

La fuerza y persistencia del poder étnico, no depende de la sintaxis del discurso y/o de las prácticas políticas desarrolladas frente al Estado y sociedad nacionales, está más en función de su gramática del poder, cuyo constreñimiento opera análogamente como la gramática de la lengua, pero con una diferencia fundamental. Mientras la gramática de la lengua se ejercita en el habla sin que el sujeto sea o necesite ser consciente de ella y se expresa en el orden de lo dicho, la gramática del poder étnico, por estar más en lo que se hace 
que en lo que se dice, puede ser vista y por tanto controlada "intencionalmente”. Tal carácter hace que el sentido hacia el poder, no sea tanto el de acceder a él individual o corporativamente, sino el de controlarlo comunalmente.

Un poder que debe desarrollarse social y políticamente sobre la base de su control comunal, quizás sea lo que hace explicable el actual del movimiento indígena en la vida nacional, pero a su vez hace más fuerte los procesos de resistencia étnicos. El posicionamiento del movimiento en el ámbito nacional, ha de hacerse no por la vía de la fuerza y el acrecentamiento del poder, sino vía de lo que culturalmente le es propio: el convencimiento, el diálogo, el consenso, el reconocimiento. El espíritu guerrero atribuido a los paeces históricamente tiene como base la defensa del río, de ahí el carácter de grupo de autodefensa que asumió el movimiento armado Quintín Lame. No fue una lucha por el poder sino contra el poder de los terratenientes, gamonales y caciques políticos, y contra el sometimiento cultural, de igual forma como lo es la Lucha del movimiento indígena en Colombia.

Estrategias de resistencia cultural de proyección política nacional sin las cuales no hubiera sido posible "conservar" hasta el presente, la diversidad de poderes étnicos y etnias y, por ende, el movimiento indígena. Esta gramática del poder constituye un eje fundamental de la diferencia étnica en Colombia y al parecer también en otros países de América Latina.

\section{Bibliografía}

Arango, Raúl, 1992: Una Visión general sobre los pueblos indígenas de Colombia, Santafé de Bogotá: DNP

Arocha, J y otros, 1987: Colombia: Violencia y Democracia, Bogotá: Universidad Nacional de Colombia.

Bobbio, Norberto, 1985: El futuro de la democracia, Barcelona Plaza y Janes

Bonfil, Batalla (Compilador), 1981: Utopía y revolución, México: Nueva Imagen

Bonfil, Batalla, 1989: México profundo. Una civilización negada, México Grijalbo

Bonfil, Batalla 1991 Pensar Nuestra cultura, México: Alianza editorial. Clastres, Pierre, 1974: La Société contre I'etat, Paris: Minrit.

Claval, Paul, 1982: Espacio y poder, México: Fondo de Cultura Económica.

Cric, 1981: "Diez años de lucha Historia y Documentos" en Controversia No 91, Bogotá: CINEP

Foucault, Michael, 1987: Vigilar y castigar, México: Siglo XXI Editores 
Gros, Christian, 1991: Colombia indígena. Identidad cultural y cambio social, Bogotá: Cerec.

Jimeno, Myriam y Adolfo Triana, 1985: Estado y minorías étnicas, Bogotá: Nueva Imagen Organización Internacional del Trabajo. OIT, 1989:

Convenio sobre pueblos indígenas y tribales en países independientes, Ginebra: OIT

Padilla, Guillermo, 1993: "Derecho mayor indígena y derecho constitucional" En Revista de ciencias sociales. Año 1. No 4 México

Paz, Octavio, 1977: El laberinto de la soledad, México: Fondo de Cultura Económica

República de Colombia, 1991: Constitución Política de Colombia, Bogotá: Temis

Reynaga, Ramiro, 1994: “El viejo topo” en Dos mundos opuestos. Entrevista de Víctor Molina

Sánchez, Parga, 1986: La Trama del poder en la comunidad andina, Quito: Centro Andino de Educación Popular.

Sánchez, Parga, 1990: Etnia poder y diferencia, Quito: Abya yala 